\title{
Not quite the last word on the Perkin reaction
}

Link to publication record in Manchester Research Explorer

\section{Citation for published version (APA):}

Edwards, M., Rourk, P. M., Riby, P., \& Mendham, A. P. (2014). Not quite the last word on the Perkin reaction. Tetrahedron, 70(40), 7245-7252.

\section{Published in:}

Tetrahedron

\section{Citing this paper}

Please note that where the full-text provided on Manchester Research Explorer is the Author Accepted Manuscript or Proof version this may differ from the final Published version. If citing, it is advised that you check and use the publisher's definitive version.

\section{General rights}

Copyright and moral rights for the publications made accessible in the Research Explorer are retained by the authors and/or other copyright owners and it is a condition of accessing publications that users recognise and abide by the legal requirements associated with these rights.

\section{Takedown policy}

If you believe that this document breaches copyright please refer to the University of Manchester's Takedown Procedures [http://man.ac.uk/04Y6Bo] or contact uml.scholarlycommunications@manchester.ac.uk providing relevant details, so we can investigate your claim.

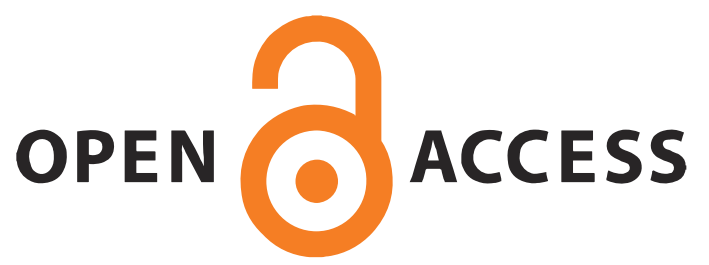




\title{
Not quite the last word on the Perkin reaction
}

\author{
Mark Edwards ${ }^{\mathrm{a}, * \dagger}$, , Paul M. Rourk ${ }^{\mathrm{d}}$, Philip G. Riby ${ }^{\mathrm{b}}$, Andrew P. Mendham ${ }^{\mathrm{c}}$ \\ ${ }^{a}$ School of Science, Grenville Building, University of Greenwich, Medway Campus, ME4 4TB, UK \\ b James Parsons Building, Liverpool John Moores University, Byrom Street, Liverpool L3 3AF, UK \\ ${ }^{c}$ Faculty of Engineering and Science, Nelson Building, University of Greenwich, Medway Campus, ME4 4TB, UK \\ ${ }^{\mathrm{d}}$ University of Greenwich, School of Chemical and Life Sciences, Wellington Street, Woolwich, London SE18 6PF, UK
}

\section{A R T I C L E I N F O}

\section{Article history:}

Received 24 April 2014

Received in revised form 11 July 2014

Accepted 14 July 2014

Available online 22 July 2014

\section{Keywords:}

Perkin reaction

Microwave

Water

PFA vessels

Mechanism proposal

\begin{abstract}
A B S T R A C T
Microwave irradiation does not accelerate the rate of the Perkin reaction carried out under normal atmospheric pressure. Water is an essential yet catalytic reactant for the Perkin reaction to occur. Containment of the Perkin reaction in a sealed vessel improves the yield. Two pressure increases are observed during a $4 \mathrm{~h}$ reaction time. An induction period is seen in the Perkin reaction when sodium acetate is used as a base. A re-appraisal of the reaction mechanism is proposed on the basis of these observations. The use of $\mathrm{PFA}^{\circledR}$ reaction vessels enables the Perkin reaction to occur under aqueous conditions for around 80 reactions/vessel.
\end{abstract}

(ㄷ) 2014 Elsevier Ltd. All rights reserved.

\section{Introduction}

Interest in applying microwave heating to organic reactions had been awakened by Gedye and others in the early $1990 \mathrm{~s},{ }^{1,2}$ and these applications to synthesis followed indirectly from Kingston's work on using microwave heating for analytical sample preparation alongside the simultaneous development of commercial ovens to produce the microwave heating effect by CEM amongst others. ${ }^{3,4}$

Around 20 years ago, the Perkin reaction, which involves the use of an inorganic acetate salt in acetic anhydride to convert a variety of aromatic aldehydes into their corresponding 3-phenylprop-2enoic acids, seemed a suitable model reaction to study the heating effects of microwaves. ${ }^{5}$ The reaction is well-known, uses readily available reactants and, since most synthetic methods describe up to an $8 \mathrm{~h}$ synthesis, ${ }^{6,7}$ the reaction would benefit from the reaction rate enhancement that is reported as a beneficial effect of microwave heating for organic synthesis. ${ }^{8}$

\section{Results and discussion}

Before embarking on a study of the microwave-assisted Perkin reaction it was important to ensure that an optimised thermal

\footnotetext{
* Corresponding author. c/o Andy Mendham, Faculty of Engineering and Science, University of Greenwich, Medway Campus, Kent ME4 4TB, UK; e-mail address: a.p. mendham@gre.ac.uk (M. Edwards).

$\dagger$ Retired.
}

heating method was being used. The status of experimental information on the Perkin reaction at the time could be summarised perfectly by Johnson's words in his review ${ }^{6}$ published many years earlier: 'A number of studies have been made of factors influencing the yields in the Perkin reaction, but it is difficult to draw any broad generalizations'.

Clearly, this situation was unsatisfactory and it was important to establish a stable and optimised baseline from which to measure any possible improvements. Scheme 1 illustrates the particular version of the Perkin reaction that we wished to study.

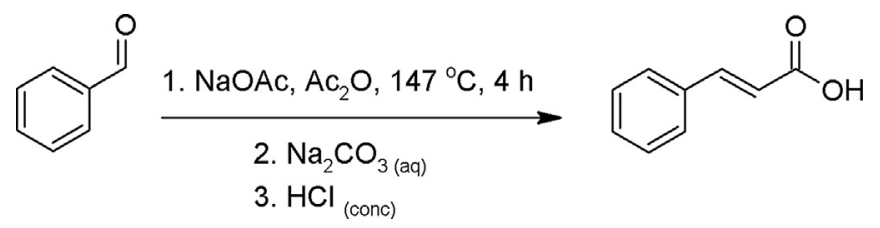

Scheme 1. The particular version of the Perkin reaction under study in this paper.

We used mass balance calculations, based upon benzaldehyde input, in order to determine cinnamic acid product losses to the waste-streams generated during work-up of the reactions. Modifications to the reactions and their associated work-up procedures were driven by the results obtained by these mass balance calculations and were important in the development of a consistently repeatable reaction. TLC analyses against standards of known 
cinnamic acid concentration were used to estimate waste-stream losses in the absence of a validated HPLC method. Table 1 shows how these estimates compared with the actual quantities isolated from the waste-streams examined.

Table 1

Reliability check for TLC estimation of organic extract cinnamic acid content

\begin{tabular}{lll}
\hline Run number & $\begin{array}{l}\text { TLC estimated cinnamic acid } \\
\text { content, \% molar yield }\end{array}$ & $\begin{array}{l}\text { Recovered cinnamic } \\
\text { acid, \% molar yield }\end{array}$ \\
\hline $2-6$ & $7.32 \pm 0.53$ & $7.14 \pm 0.56$ \\
$10-12$ & $9.8 \pm 0.83$ & $9.62 \pm 1.04$ \\
$13-15$ & $4.32 \pm 2.55$ & $3.87 \pm 2.13$ \\
$22-25$ & $0.75 \pm 0.17$ & $0.59 \pm 0.14$ \\
\hline
\end{tabular}

The TLC estimates in Table 1 are consistent, and correlate with the recovered yields of cinnamic acid. TLC, although a semiquantitative analytical method, has been reported to be useful in the estimation of active ingredients in drug formulation studies. ${ }^{9}$ Kadin reported that in 15 TLC assays of Captopril in spiked placebo powders recovery was $100.6 \%$ with a standard deviation of $1.39 \%$ and a coefficient of variation of 1.38 . Clearly TLC is useful, in certain cases, as a quick, semi-quantitative analytical method provided that certain experimental conditions are adhered to during its application. TLC plate loading is important and specific to the TLC plate manufacture. Experience has shown that for the TLC plates used in this study, no more than $100 \mu \mathrm{g}$ loading of a wastestream sample from a $5 \mu \mathrm{L}$ micropipette provides uniformly-sized TLC spots. The optical density of the developed waste-stream spot, under UV $254 \mathrm{~nm}$ light, can be compared against a range of different concentrations of reference standard TLC spots, which have been carefully prepared from commercial cinnamic acid. A process of trial and error quickly enables suitable concentrations of TLC reference standard spots to be found and used for comparison with each analytical sample in this semi-quantitative method. The reference standard TLC spots are applied using fresh, $5 \mu \mathrm{L}$ micropipettes, and are developed simultaneously alongside the wastestream sample, on the same TLC plate. TLC tank solvent/vapour equilibration is important if consistent TLC spot $R_{f}$ values and TLC plate performance are required. Solvent vapour/liquid equilibration times of around $20 \mathrm{~min}$, for a $20 \times 20 \mathrm{~cm}$ glass TLC tank at $24-25^{\circ} \mathrm{C}$ were found satisfactory for TLC plate development, if chromatography paper wicks are used inside the TLC tank in order to aid solvent evaporation.

Once an estimate of the waste-stream TLC spot concentration has been made, the result can be factored into the preparation of the analytical sample and calculated back to the original volume of the waste-stream under analysis.

We developed a reaction procedure that provided a consistent and stable yield platform from which to measure any improvements and from which we were able to critique the validity of some of the points reported by Johnson in his review under the section entitled 'Selection of experimental conditions'.

The results obtained from our method shown in Table 2 are consistent with those described by Kalnin and Böck et al. ${ }^{10,11}$

Disappointingly, Perkin reactions, using our updated $4 \mathrm{~h}$ version of the method described by Vogel, when performed in standard laboratory glassware in a CEM MARS300 modified oven did not provide any evidence for rate acceleration by microwave heating over that provided by standard thermal heating.

This observation with sodium acetate as base was later confirmed by Veverkova et al., in their microwave study of the Perkin reaction. ${ }^{12}$

Interestingly, the average yield obtained from six microwave reactions was almost identical with the yield obtained from runs $2-6$, in Table 4, based upon the original stoichiometry for the reaction proposed by Perkin and published as a cognate method by
Table 2

Yields obtained from a modified, 4 h Perkin reaction using sodium acetate as base

\begin{tabular}{llllll}
\hline $\begin{array}{l}\text { Run } \\
\text { number }\end{array}$ & $\begin{array}{l}\text { Molar ratios, } \\
\text { benzaldehyde: } \\
\text { sodium acetate: } \\
\text { acetic anhydride }\end{array}$ & $\begin{array}{l}\text { Isolated } \\
\text { cinnamic } \\
\text { acid \% } \\
\text { molar } \\
\text { yield }\end{array}$ & $\begin{array}{l}\text { Total cinnamic } \\
\text { acid \% molar } \\
\text { yield based on } \\
\text { mass balance } \\
\text { calculations }\end{array}$ & $\begin{array}{l}\text { Mean total } \\
\text { cinnamic } \\
\text { acid \% molar } \\
\text { yield }\end{array}$ & $\begin{array}{l}\text { Standard } \\
\text { deviation, }\end{array}$ \\
$\sigma_{n-1}$ \\
\hline 11 & $1.0: 1.0: 2.3$ & 13.7 & 24.5 & 24.0 & 0.53 \\
13 & & 13.6 & 24.4 & & \\
14 & & 13.6 & 25.0 & & \\
35 & 17.8 & 23.6 & & \\
36 & 17.6 & 23.8 & & \\
37 & 17.6 & 23.5 & & \\
38 & & 18.0 & 23.9 & & \\
39 & & 17.7 & 23.6 & & \\
40 & & 17.9 & 23.5 & & \\
\hline
\end{tabular}

Vogel in the third edition of his world renowned book 'Practical Organic Chemistry'.

At the time, the comparison of these early results clouded our judgement as to the significance of the low yield obtained using microwave irradiation with our method.

During the early stages of this exploratory work, our reaction conditions needed to be defined more clearly than those originally provided by Perkin himself and the many others who followed. Using sodium acetate we found that the Perkin reaction mixture reflux occurred around $147{ }^{\circ} \mathrm{C}$, whereas when potassium acetate was used reflux occurred at $169^{\circ} \mathrm{C}$. We found that excessive heating of reaction mixtures was deleterious to the quality of the product obtained. Reaction mixtures heated in oil-baths at $180{ }^{\circ} \mathrm{C}$ were often dark-coloured and the crude products were often contaminated with tarry side-products, which were difficult to work-up and eliminate. We consider that the conclusions of Bock et al., ${ }^{11}$ and Meyer and Beer, ${ }^{13}$ with respect to using a higher reaction heating temperature, are neither conducive to ease of work-up nor the production of good quality cinnamic acids.

We had found (see Table 4) that reaction yields could be improved if the stoichiometric ratios of reactants, used by Vogel, for aromatic aldehyde, sodium acetate and acetic anhydride of 1.0:0.61:1.42 were amended in favour of 1.0:1.0:1.42. This change in stoichiometry seemed reasonable in the light of the mechanistic understanding for the Perkin Reaction, if sodium acetate was acting as a base to generate the enolate anion of acetic anhydride. ${ }^{14} \mathrm{Al}-$ though the yield improvement was only about $15 \%$ relative, we considered it helpful when running reactions for a limited time period of $4 \mathrm{~h}$ that would be expected to reduce the overall yield obtained from a reported $8 \mathrm{~h}$ reaction.

Solubility of the metal salt would be expected to have an influence on the rate of reaction. Potassium acetate is much more soluble in acetic anhydride than sodium acetate. However, with sodium acetate the yield increase is not linearly proportional to the amount of extra acetic anhydride added beyond a stoichiometric ratio of 1.42 relative to the aromatic aldehyde. As can be seen from Table 5 below, a 20\% relative increase in yield was obtained when the stoichiometric ratio of acetic anhydride was raised to 2.3 versus the molar quantity of benzaldehyde. This yield improvement was achieved at a cost of increasing the yield standard deviation. This variation in standard deviation might be expected from the extra experimental variabilities arising from the need to decompose excess acetic anhydride and then generate $\mathrm{pH} 10$ during an aqueous work-up in the presence of the additional acetic acid formed.

The yields detailed in Table 5 were then compared with the use of a stoichiometric amount of a phase transfer agent, tetrabutylammonium hydrogen sulfate. It was hoped that metathetical exchange of the sodium ion by the tetrabutylammonium ion would increase the solubility of the acetate counter-ion and thereby improve the yield of the reaction. Table 6 below shows that this 
Table 3

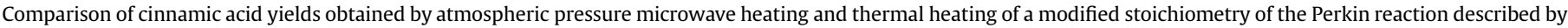
Vogel

\begin{tabular}{|c|c|c|c|c|c|c|}
\hline Reaction number & Heating method & $\begin{array}{l}\text { Molar ratios, benzaldehyde: } \\
\text { sodium acetate:acetic } \\
\text { anhydride }\end{array}$ & $\begin{array}{l}\text { Isolated cinnamic } \\
\text { acid \% molar yield }\end{array}$ & $\begin{array}{l}\text { Total cinnamic acid \% } \\
\text { molar yield based on } \\
\text { mass balance calculations }\end{array}$ & $\begin{array}{l}\text { Mean total cinnamic } \\
\text { acid \% molar yield }\end{array}$ & $\begin{array}{l}\text { Standard deviation, } \\
\sigma_{n-1}\end{array}$ \\
\hline 23 & Microwave & $1.0: 1.0: 2.3$ & 12.15 & 17.2 & 17.6 & 0.57 \\
\hline 24 & & & 11.86 & 18.2 & & \\
\hline 25 & & & 11.96 & 17.4 & & \\
\hline 26 & & & 12.15 & 17.3 & & \\
\hline 27 & & & 12.15 & 17.2 & & \\
\hline 28 & & & 11.66 & 18.5 & & \\
\hline $11,13,14,35-40$ & Thermal & $1.0: 1.0: 2.3$ & - & - & 24.0 & 0.53 \\
\hline
\end{tabular}

Table 4

Comparison of cinnamic acid yields using Vogel's stoichiometry with that arising from a prior experimental revision ${ }^{7,10}$

\begin{tabular}{|c|c|c|c|c|c|}
\hline $\begin{array}{l}\text { Reaction } \\
\text { number }\end{array}$ & $\begin{array}{l}\text { Molar ratios, benzaldehyde: } \\
\text { sodium acetate:acetic } \\
\text { anhydride }\end{array}$ & $\begin{array}{l}\text { Isolated cinnamic acid \% } \\
\text { molar yield }\end{array}$ & $\begin{array}{l}\text { Total cinnamic acid \% } \\
\text { molar yield based on } \\
\text { mass balance calculations }\end{array}$ & $\begin{array}{l}\text { Mean total cinnamic } \\
\text { acid \% molar yield }\end{array}$ & $\begin{array}{l}\text { Standard deviation, } \\
\sigma_{n-1}\end{array}$ \\
\hline 2 & 1.0:0.62:1.42 & 10.2 & 17.6 & 17.5 & 0.56 \\
\hline 3 & & 10.5 & 17.7 & & \\
\hline 4 & & 10.3 & 17.2 & & \\
\hline 5 & & 10.3 & 16.7 & & \\
\hline 6 & & 10.4 & 18.2 & & \\
\hline 7 & $1.0: 1.0: 1.42$ & 10.7 & 20.3 & 20.2 & 0.29 \\
\hline 8 & & 10.9 & 20.0 & & \\
\hline 9 & & 10.7 & 20.2 & & \\
\hline 12 & & 10.8 & 20.1 & & \\
\hline
\end{tabular}

Table 5

Yield comparison with stoichiometric variation of acetic anhydride

\begin{tabular}{|c|c|c|c|c|c|}
\hline Run number & $\begin{array}{l}\text { Molar ratios, benzaldehyde: } \\
\text { sodium acetate:acetic } \\
\text { anhydride }\end{array}$ & $\begin{array}{l}\text { Isolated cinnamic acid \% } \\
\text { molar yield }\end{array}$ & $\begin{array}{l}\text { Total cinnamic acid \% } \\
\text { molar yield based on } \\
\text { mass balance } \\
\text { calculations }\end{array}$ & $\begin{array}{l}\text { Mean total cinnamic } \\
\text { acid \% molar yield }\end{array}$ & $\begin{array}{l}\text { Standard deviation, } \\
\sigma_{n-1}\end{array}$ \\
\hline $7-9,12$ & $1.0: 1.0: 1.42$ & - & - & 20.2 & 0.29 \\
\hline 11 & $1.0: 1.0: 2.3$ & 13.7 & 24.5 & 24.0 & 0.53 \\
\hline 13 & & 13.6 & 24.4 & & \\
\hline 14 & & 13.6 & 25.0 & & \\
\hline 35 & & 17.8 & 23.6 & & \\
\hline 36 & & 17.6 & 23.8 & & \\
\hline 37 & & 17.6 & 23.5 & & \\
\hline 38 & & 18.0 & 23.9 & & \\
\hline 39 & & 17.7 & 23.6 & & \\
\hline 40 & & 17.9 & 23.5 & & \\
\hline
\end{tabular}

hypothesis was confirmed by a $25 \%$ relative increase in overall cinnamic acid \% molar yield. Interestingly the yields obtained with potassium acetate over the same time period of $4 \mathrm{~h}$ were significantly better than those obtained with sodium acetate with or without phase transfer agent. We suggest this is due to the greater solubility of the potassium salt, when compared with the others. The improved solubility results in a higher reaction mixture reflux temperature, a faster reaction and a completely homogeneous reaction mixture without any suspended salts such as sodium hydrogen sulfate.

However, because of the elevated reaction mixture reflux temperatures achieved, the reaction products from potassium acetate $\left(169{ }^{\circ} \mathrm{C}\right)$ and phase transfer agent modified $\left(163{ }^{\circ} \mathrm{C}\right)$ Perkin reactions contained significant amounts of a tarry-like material. The

Table 6

Comparison of cinnamic acid molar yields obtained using tetrabutylammonium hydrogen sulfate with sodium acetate, potassium acetate or sodium acetate alone

\begin{tabular}{|c|c|c|c|c|c|c|}
\hline Run number & $\begin{array}{l}\text { Molar ratios benzaldehyde: } \\
\text { metal salt:acetic anhydride }\end{array}$ & Metal salt & $\begin{array}{l}\text { Isolated cinnamic } \\
\text { acid \% molar yield }\end{array}$ & $\begin{array}{l}\text { Total cinnamic acid, } \\
\% \text { molar yield based } \\
\text { on mass balance } \\
\text { calculations }\end{array}$ & $\begin{array}{l}\text { Average total cinnamic } \\
\text { acid \% molar yield }\end{array}$ & $\begin{array}{l}\text { Standard deviation, } \\
\sigma_{n-1}\end{array}$ \\
\hline $11,13,14,35-40$ & $1.0: 1.0: 2.3$ & $\mathrm{NaOAC}$ & - & - & 24.0 & 0.53 \\
\hline 17 & $1.0: 1.0: 1.0: 2.3$ & $\mathrm{NaOAC}+\mathrm{Bu}_{4} \mathrm{NHSO}_{4}$ & 25.8 & 30.5 & 30.9 & 0.69 \\
\hline 18 & & & 25.0 & 30.5 & & \\
\hline 19 & & & 30.2 & 31.7 & & \\
\hline 20 & $1.0: 1.0: 2.3$ & KOAC & 68.3 & 68.9 & 69.1 & 0.51 \\
\hline 21 & & & 68.7 & 69.2 & & \\
\hline 22 & & & 68.9 & 69.7 & & \\
\hline 23 & & & 68.0 & 68.5 & & \\
\hline
\end{tabular}


tarry crude products required prolonged heating with sodium carbonate solutions in order to effect complete dissolution and achievement of a stable $\mathrm{pH}$ value of 10 during work-up. On the other hand, work-up of sodium acetate Perkin reactions were easier and product quality obtained was initially better with sodium acetate because negligible tarry-product was produced, as a result of the controlled, lower reaction mixture reflux temperature.

Use of $300{ }^{\circ} \mathrm{C}$ in order to prepare 'freshly fused' sodium acetate, as recommended by Perkin, was found to be unnecessary by TG analysis. TG analysis in Fig. 1 clearly shows that the majority of any water of crystallisation or surface adsorption is lost by $158^{\circ} \mathrm{C}$. Moreover, the lower drying temperature we chose for sodium acetate of $265^{\circ} \mathrm{C}$, avoided the possible onset of decomposition, found to be around $304-308{ }^{\circ} \mathrm{C}$ during TG analysis (see Fig. 1 ), which we had noted earlier in the study, when we had used a muffle-furnace set-temperature of $300{ }^{\circ} \mathrm{C}$.

It was decided that with a sound set of revised reaction conditions for thermal and microwave heating we should turn our in-

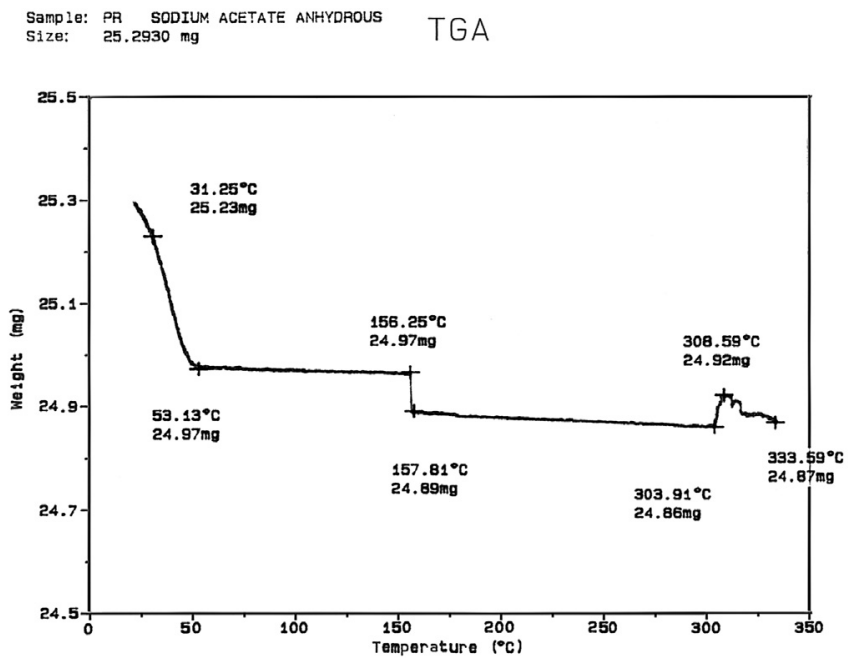

Fig. 1. TGA analysis of anhydrous sodium acetate. Heating rate, $5^{\circ} \mathrm{C} \mathrm{min}^{-1}$, under static air with pierced aluminium pan. TGA shows about $1.59 \% \mathrm{w} / \mathrm{w}_{2} \mathrm{O}$ in this sample of anhydrous sodium acetate.

terest toward using perfluoroalkoxy, PFA ${ }^{\circledR}$, polymer liners that were provided with the advanced composite vessels, ACV's, of the CEM MDS2100 microwave oven, rather than just standard laboratory glassware in an older, modified CEM MAS300 microwave oven. Previously, PFA ${ }^{\circledR}$ vessels had been shown to be advantageous in analytical digestion work because of the increased pressure and temperature available to the digestion process. ${ }^{15}$

The PFA ${ }^{\circledR}$ vessels that we used were translucent, unused and had a nominal capacity around $75 \mathrm{~mL}$.

We had observed in the earlier atmospheric pressure microwave heated reactions that the calcium chloride granules present in the guard tube attached to the top of the apparatus assembly had become fused together. The reason for this fusion was not clear as temperatures measured at the top of the reactor assembly had not increased above room temperature at any point. The low temperatures recorded discounted any leakage of hot acetic acid or acetic anhydride vapours past the condenser. Reflux of the reaction mixture had been observed in the glass apparatus within the cavity of the CEM MAS300 microwave oven at a much lower point than where the guard tube was attached to the reactor condenser assembly. We considered, as a possibility that an unknown, volatile, microwave active intermediate had passed from the microwave cavity through the condenser and reacted with the calcium chloride granules. It was noted that the fused calcium chloride granules smelt strongly of acetic acid when washed from the guard tube following equipment disassembly. If escape of a highly volatile reactive species was occurring, it might explain why the yields we had obtained from atmospheric microwave Perkin reactions were lower than expected (See Table 3).

The PFA ${ }^{\circledR}$ polymer-lined advanced composite vessels could be sealed and this would prevent the escape of any volatile material. Pressure and temperature measurements of a control vessel, which was included in every microwave oven run, for programme control, safety considerations and temperature feedback, could be made. Unfortunately, the reliability of the control vessel yield measurements was questionable when non-aqueous solvents were used. This is because the pressure measurements relied on water to transfer the pressure in the control vessel via a Teflon tube to a transducer within the microwave oven control box. We thought that the water in the pressure transfer line might react with volatile or reactive intermediates in the control vessel or contaminate the reaction within, rendering yield measurements meaningless.

Inspection of Table 7 above shows that the overall \% molar yield of cinnamic acid in the sealed vessels was more than twice that of the atmospheric pressure reactions carried out in standard laboratory glassware. The improvement in yield from sealed vessels, along with the observation of fused calcium chloride granules in the guard tubes and the lower than expected yields of the atmospheric, microwave Perkin reactions provided strong evidence for the presence of a key, gaseous, reactive intermediate, possibly ketene, as postulated by Kinastowski, in his work on the mechanism of the Perkin reaction when catalysed by tertiary amine. ${ }^{16}$

Pressure values obtained from the control vessel, shown in Fig. 2, provide additional evidence for this postulate through two, clear, pressure increases in the control vessel during the reaction. One pressure increase was observed at $1 \mathrm{~h}$ and the other at $3 \mathrm{~h}$. Repeatedly we had observed an induction period of about $60 \mathrm{~min}$ when sodium acetate was used as the base in our Perkin reactions. These observations had been made when conducting semiquantitative TLC analyses against a variety of known concentration standards. No induction period was observed, either when potassium acetate was used as base, or when tetrabutylammonium hydrogen sulfate was used in conjunction with sodium acetate. Indeed, we considered that the latter observation with the immediate formation of a very fine precipitate in the reaction mixtures

Table 7

Comparison of atmospheric pressure and sealed microwave vessel Perkin reactions

\begin{tabular}{|c|c|c|c|c|c|c|}
\hline $\begin{array}{l}\text { Reaction } \\
\text { number }\end{array}$ & Reaction type & $\begin{array}{l}\text { Molar ratios, benzaldehyde: } \\
\text { sodium acetate:acetic } \\
\text { anhydride }\end{array}$ & $\begin{array}{l}\text { Isolated cinnamic } \\
\text { acid \% molar yield }\end{array}$ & $\begin{array}{l}\text { Total cinnamic acid } \\
\% \text { molar yield based } \\
\text { on mass balance } \\
\text { calculations }\end{array}$ & $\begin{array}{l}\text { Mean total \% } \\
\text { molar yield }\end{array}$ & $\begin{array}{l}\text { Standard deviation, } \\
\sigma_{n-1}\end{array}$ \\
\hline $23-28$ & Atmospheric & $1.0: 1.0: 2.3$ & - & - & 17.6 & 0.57 \\
\hline 29 & Sealed & $1.0: 1.0: 2.3$ & 28.2 & 36.5 & 36.3 & 0.29 \\
\hline 30 & & & 28.8 & 36.1 & & \\
\hline 31 & & & 29.0 & 36.7 & & \\
\hline 32 & & & 28.8 & 36.3 & & \\
\hline 33 & & & 28.7 & 35.9 & & \\
\hline 34 & & & 28.9 & 36.4 & & \\
\hline
\end{tabular}


Perkin reaction pressure / temperature data

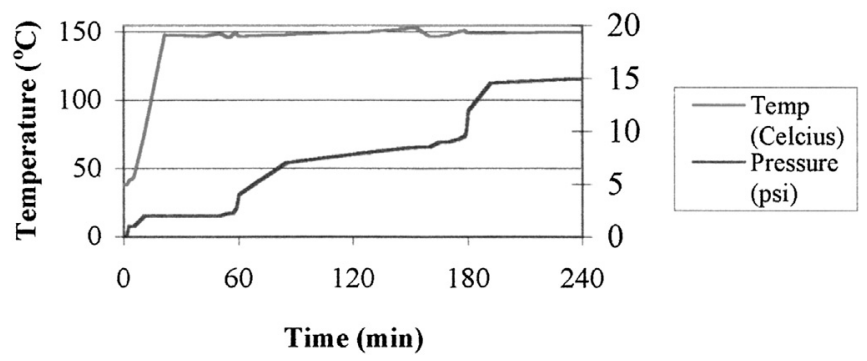

Fig. 2. Perkin reaction pressure and temperature profiles obtained in the CEM MDS2100 oven using PFA ${ }^{\circledR}$-lined ACV's.

were good indications that a quick, metathetical exchange of sodium ions for tetrabutylammonium cations had occurred.

We do not know the reason(s) for this induction period with sodium acetate. However, work published by Veverkova et al., on microwave-stimulated Perkin reactions stated that no Cinnamic acid was formed after $60 \mathrm{~min}$ of irradiation at $800 \mathrm{~W}$, when sodium acetate was used as the base, ${ }^{15}$ which supports our own experimental observations.

At the time we were uncertain if the PFA ${ }^{\circledR}$ vessels had interacted in some way with the microwave irradiation. It was decided therefore to conduct a series of thermally heated reactions in the same vessels using an oil-bath.

Both sets of reactions, detailed in Tables 7 and 8, were performed at $147{ }^{\circ} \mathrm{C}$. However, the oil-bath was heated to $155^{\circ} \mathrm{C}$ and it took around $18 \mathrm{~min}$ for the $\mathrm{PFA}^{\circledR}$ vessels to reach $147^{\circ} \mathrm{C}$. As a result of the delay, the thermally heated vessel reactions listed in Table 8 , had a longer overall reaction time $(+7.5 \%$ relative). This discrepancy between the two reaction sets adequately accounts for the slightly higher yields observed ( $+7.4 \%$ relative) from the thermally heated vessels. programme it became evident very quickly that prior vessel usage had a considerable effect on synthesis yields of the Perkin reaction (Table 9).

Aware of the possible impact on other synthetic work, as well as chemical analyses, an alternative and quicker, vacuum decontamination method was developed by Riby et al. ${ }^{17}$

The newer method, which involved heating $\mathrm{PFA}^{\circledR}$ vessels to $155^{\circ} \mathrm{C}$ at $6 \mathrm{mmHg}$ pressure, was used because of its time-saving aspect of around 66 h over the saturated sodium carbonate solution decontamination soak.

The new decontamination method had a devastating effect upon the yields of the Perkin reaction conducted in thermally heated, PFA ${ }^{\circledR}$ vessels.

It can be seen from Table 10 that removal of volatile contaminants such as acid and water from the PFA ${ }^{\circledR}$ vessel material led to no observed reaction. This observation was a complete surprise and it became important to ascertain what roles water and the vessel wall material, PFA ${ }^{\circledR}$ played. It is important to note that the decontaminated vessels were immediately charged with reactants when taken out of the vacuum oven, which was held at $155^{\circ} \mathrm{C}$ during the

Table 10

Effect of vacuum decontamination procedure on Perkin yields in sealed PFA ${ }^{\circledR}$ vessels

\begin{tabular}{lll}
\hline Reaction number & $\begin{array}{l}\text { Isolated cinnamic } \\
\text { acid \% molar yield }\end{array}$ & $\begin{array}{l}\text { Total cinnamic acid \% } \\
\text { molar yield from } \\
\text { mass balance } \\
\text { calculations }\end{array}$ \\
\hline $54-56$ & 0.0 & 0.0 \\
$57-59$ & 0.0 & 0.0 \\
Control vessel & 0.0 & 10.7 \\
$\quad$ for runs 54-56 & 0.0 & 11.0 \\
Control vessel & \\
$\quad$ for runs 57-59 & & \\
\hline
\end{tabular}

Table 8

Comparison of thermal and microwave heating of Perkin reactions in PFA ${ }^{\circledR}$ vessels with benzaldehyde, sodium acetate and acetic anhydride molar ratios of 1.0:1.0:2.3

\begin{tabular}{|c|c|c|c|c|c|}
\hline Run number & $\begin{array}{l}\text { Heating } \\
\text { method }\end{array}$ & $\begin{array}{l}\text { Isolated cinnamic } \\
\text { acid \% molar yield }\end{array}$ & $\begin{array}{l}\text { Total cinnamic acid \% } \\
\text { molar yield based on } \\
\text { mass balance } \\
\text { calculations }\end{array}$ & $\begin{array}{l}\text { Mean total cinnamic } \\
\text { acid \% molar yield }\end{array}$ & Standard deviation \\
\hline $29-34$ & Microwave & - & - & 36.3 & 0.29 \\
\hline 41 & Thermal & 29.1 & 38.8 & 39.0 & 0.29 \\
\hline 42 & & 29.2 & 39.1 & & \\
\hline 43 & & 28.9 & 39.4 & & \\
\hline 45 & & 29.3 & 39.2 & & \\
\hline 46 & & 28.7 & 38.6 & & \\
\hline 47 & & 29.5 & 39.1 & & \\
\hline
\end{tabular}

Up to this point a limited number of unused, assumed clean PFA $^{\circledR}$ vessels had been utilised for this study. More PFA ${ }^{\circledR}$ vessels were available but these had been used for acidic, analytical digestion work. When these were incorporated into the synthetic decontamination procedure. Moreover, the sodium acetate used was freshly dried at $265^{\circ} \mathrm{C}$ and similarly was taken directly from the drying oven prior to charging the freshly decontaminated vessels with reactants.

Table 9

Effect of prior acid digestion usage on Perkin reaction yields and the effect of a $72 \mathrm{~h}$ sodium carbonate solution decontamination soak on PFA ${ }^{\circledR}$ vessel performance

\begin{tabular}{|c|c|c|c|c|c|}
\hline $\begin{array}{l}\text { Reaction } \\
\text { number }\end{array}$ & Prior usage & $\begin{array}{l}\text { Isolated cinnamic } \\
\text { acid \% molar yield }\end{array}$ & $\begin{array}{l}\text { Total cinnamic } \\
\text { acid \% molar } \\
\text { yield based on } \\
\text { mass balance } \\
\text { calculations }\end{array}$ & $\begin{array}{l}\text { Mean total cinnamic } \\
\text { acid \% molar yield }\end{array}$ & $\begin{array}{l}\text { Standard deviation, } \\
\sigma_{n-1}\end{array}$ \\
\hline $47 a$ & Acid digestion & 0.0 & 0.0 & 6.3 & 6.1 \\
\hline $47 b$ & Second Perkin & 1.7 & 3.1 & & \\
\hline $47 c$ & Third Perkin & 5.2 & 8.3 & & \\
\hline $47 d$ & Fourth Perkin & 10.4 & 13.9 & & \\
\hline 50 & $72 \mathrm{~h} \mathrm{Na}_{2} \mathrm{CO}_{3}$ decon. & 29.0 & 38.8 & 39.1 & 0.25 \\
\hline 51 & & 30.1 & 39.4 & & \\
\hline 52 & & 29.5 & 39.1 & & \\
\hline 53 & & 29.4 & 39.1 & & \\
\hline
\end{tabular}


It is clear from Table 10 above that the control vessels, which have a water transfer line and fibre optic temperature probe attached, allowed the Perkin reaction to proceed, although in lower yield than previously seen. It was postulated that water present in the PFA ${ }^{\circledR}$ vessel walls had been removed by the vacuum decontamination procedure and that only the control vessels had access to water via the pressure transfer line. We felt vindicated that we had not used yield data from the control vessel when monitoring all experimental runs.

It was then decided to repeat the reactions but to deliberately add known amounts of water once the sealed vessels had cooled to room temperature.

The results are shown in Table 11.

Table 11 shows that an equivalent yield of cinnamic acid to that obtained from virgin PFA ${ }^{\circledR}$ vessels was achieved when $70 \mu \mathrm{L}$ of added water ( 3.9 mmols), roughly $1 / 18$ th the scale of these reactions based on the limiting reagent benzaldehyde. These results suggest that water is needed in catalytic quantities in order to get the Perkin

\section{Table 11}

The effect of added water to sealed PFA ${ }^{\circledR}$ vessels, decontaminated by the vacuum decontamination procedure, in the $4 \mathrm{~h}$ thermally heated Perkin reaction

\begin{tabular}{llll}
\hline $\begin{array}{l}\text { Reaction } \\
\text { number }\end{array}$ & Water added, $\mu \mathrm{L}$ & $\begin{array}{l}\text { Isolated cinnamic } \\
\text { acid \% molar yield }\end{array}$ & $\begin{array}{l}\text { Total cinnamic acid \% } \\
\text { molar yield based on } \\
\text { mass balance } \\
\text { calculations }\end{array}$ \\
\hline $54-59$ & 0.0 & 0.0 & 0.0 \\
60 & 10 & 9.6 & 11.8 \\
61 & 30 & 15.0 & 18.7 \\
62 & 70 & 31.9 & 39.2 \\
63 & 150 & 33.7 & 41.5 \\
$41-47$ & Virgin PFA $^{\circledR}$ & 29.1 mean & 39.0 mean \\
\hline
\end{tabular}

reaction to work. These facts when combined suggest that the current mechanism of the Perkin reaction is incorrect as it does not take into account our experimental observations. We thought it would be interesting to see how much water could be tolerated by the Perkin reaction when the reaction was conducted in PFA ${ }^{\circledR}$ vessels (Fig. 3).

We were astonished to find that the Perkin reaction in thermally heated PFA ${ }^{\circledR}$ vessels could tolerate up to $30 \mathrm{~mL}$ of added water. The final volume of water was restricted by the total, safe usable volume available in the PFA ${ }^{\circledR}$ vessels used.

There was, however, a catch to this unusual reaction. After 83 consecutive reactions conducted with added water in a single set of

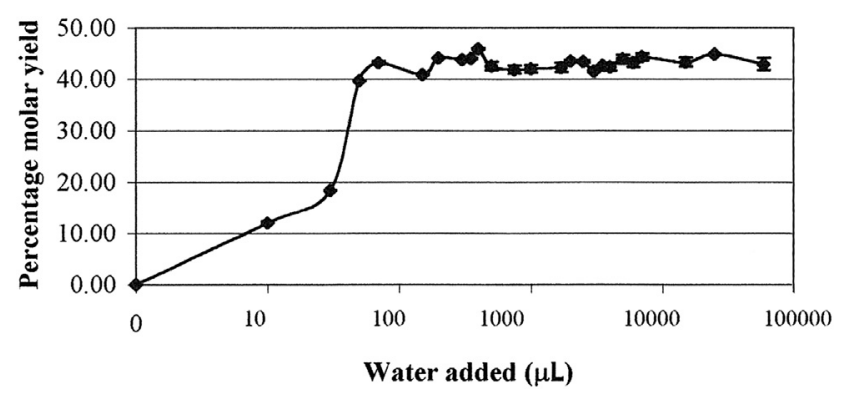

Fig. 3. A semi-logarithmic plot of the effect of added water on the yield of the Perkin reaction heated thermally in sealed $\mathrm{PFA}^{\circledR}$ vessels. Points above the $40 \%$ molar yield line are the averages of at least three runs. $1 \sigma_{n-1}$ error bars are just visible.

$\mathrm{PFA}^{\circledR}$ vessels the tolerance to added water above $2.5 \mathrm{~mL}(2 \mathrm{M}$ equivalents) ceased. It was noted at this point that the PFA ${ }^{\circledR}$ vessels had changed from being translucent to being dark brown coloured. Clearly some 'ageing' process of the PFA ${ }^{\circledR}$ polymer was taking place. The dark colour suggested charred, organic material, which the vacuum decontamination procedure did not remove. We did not reinvestigate the use of a sodium carbonate solution decontamination soak. Whatever the true nature of the 'ageing' process is, it had a profound effect on the ability of PFA ${ }^{\circledR}$ vessels to tolerate large quantities of added water in the Perkin reaction conditions that we had developed.

\section{Conclusions}

We have found that the presence of water is essential for the Perkin reaction to proceed. However, the amount of water required for this reaction is not stoichiometrically related to the other reagent molar ratios of the reaction mixture: water behaves as a catalyst. In a self-drying reaction mixture with fresh starting materials, such as that found in the Perkin reaction, adventitious ingress of water is the only way in which the reaction can proceed. Furthermore, if a non-stoichiometric amount of water is sufficient to allow the reaction to proceed to completion under our revised conditions this suggests that water is regenerated during the reaction mechanism in order to support its non-stoichiometric role. These facts suggest that anhydrous acetic acid, the sole product from the hydrolysis of acetic anhydride, plays a significant role in the Perkin reaction.

This final conclusion contrasts strongly with the earlier conclusions of Michael ${ }^{18}$ in which acetic acid was considered an inhibitor of the Perkin reaction, yet supports some of the unattributed statements of Johnson, possibly due to his student Chappell, ${ }^{19}$ in his comprehensive review.

We have shown a more than doubling of the Perkin reaction product yield with a closed reaction vessel system. We believe that the yield improvement in sealed vessels implicates the presence of volatile species, which play important roles in the success of the Perkin reaction. The two increases in pressure measurement observed reinforce this claim and suggest that two volatile intermediates are involved in the overall transformation.

Preliminary, as yet unreported, kinetic work of ours suggests that the Perkin reaction is second order when potassium acetate is used as the base. In addition, over a period of about ten years following this study, we have been unable to provide any evidence for the formation of $Z$-cinnamic acid under the carefully controlled temperature conditions specified in this work. Such a finding strongly suggests a cyclic intermediate, whose conformation ensures only E-cinnamic acid formation on ring-opening.

We believe that this study supports the original proposition of Kinastowski that ketene reacts with benzaldehyde to form an oxetan-2-one intermediate. This study provides evidence for the mechanism of formation of ketene by attack of the acetate ion on the active methyl group of acetic acid, initially generated from the adventitious hydrolysis of acetic anhydride causing the elimination of water from anhydrous acetic acid across its carbonyl function. We believe that the mechanism presented in Scheme 2 is a better mechanistic representation of Perkin's serendipitous reaction and should, if proven, supplant all current, published named reaction mechanisms. $^{20}$

All that we lack is the direct spectroscopic evidence for the proposed, four membered $\beta$-lactone.

The proposed intermediate, although racemic, should possess interesting chemical shift and coupling data for comparison with current ${ }^{1} \mathrm{H}$ NMR spectrum prediction software packages because of the adjacent chiral and pro-chiral centres as well as the strained geometry of the oxetan-2-one ring system.

\section{Experimental}

\subsection{General}

Acetic Anhydride, benzaldehyde and tetrabutylammonium hydrogen sulfate were purchased from Sigma-Aldrich Company Ltd. 
<smiles>CC(=O)CCCCCCC(=O)OC(C)=O</smiles>

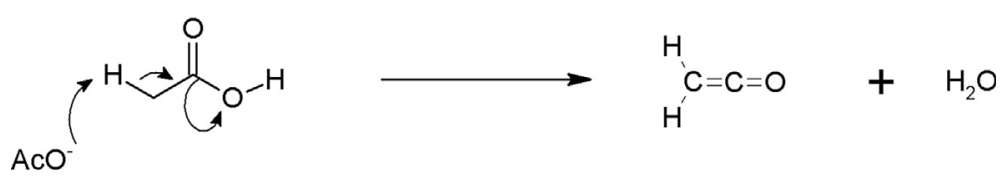

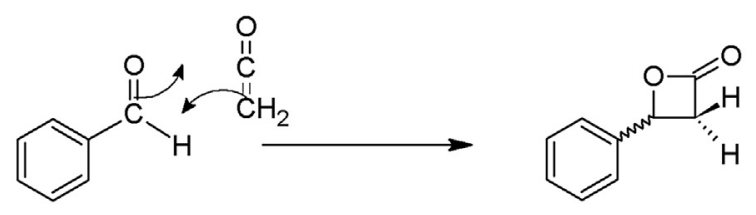

4-phenyloxetan-2-one

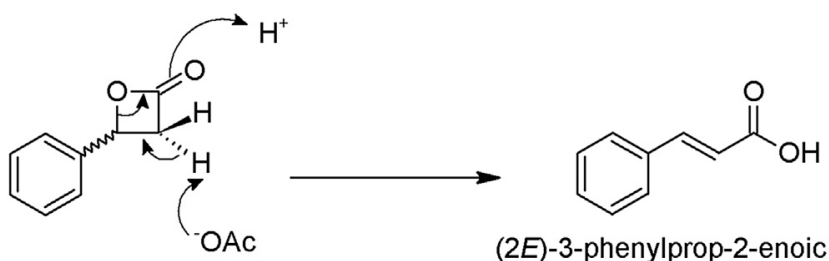

(2E)-3-phenylprop-2-enoic acid

Scheme 2. Mechanism proposed for the Perkin reaction based on observations made during this study.

Anhydrous sodium acetate and anhydrous potassium acetate were supplied by Lancaster Synthesis Ltd., UK. All reagents were used directly without further purification. All solvents were supplied by Fisher Scientific, Loughborough, UK and used without further purification. Reagents were weighed on a Sartorius BA310S top pan balance. Anhydrous sodium acetate was dried in a Carbolite EML Eurotherm muffle-furnace at set-temperatures of 300 or $265^{\circ} \mathrm{C}$ for at least $3 \mathrm{~h}$. Microwave reactions were performed in either a modified CEM MAS300 $800 \mathrm{~W}$, or a CEM MDS2100, $1000 \mathrm{~W}$ multi-mode microwave ovens. The MAS300 oven was modified by CEM UK, Ltd., with the middle of the top surface of the oven drilled with three adjacent holes ( 2 side holes $\times 20 \mathrm{~mm}$ diameter and one central hole $\times 40 \mathrm{~mm}$ diameter), which were fitted with three metal, threaded chokes to prevent escape of microwave radiation. A Holaday, HI-1501, $2450 \mathrm{MHz}$ microwave oven radiation leak detector survey meter was used to ensure microwave leakage was absent $\left(<5 \mathrm{~mW} / \mathrm{cm}^{2}\right)$ from the modified oven during each run. Atmospheric pressure microwave reactions were carried out in standard laboratory glassware in the modified, CEM MAS300 oven. Sealed microwave reactions were carried out in PFA ${ }^{\circledR}$ liners contained in Advanced Composite Vessels as supplied by CEM UK, Ltd., within the CEM MDS2100 oven. Thermogravimetric analyses were performed using a DuPont 951 thermogravimetric analyser using V4.10 DuPont 2000 controller software. Thermal reactions were carried out using an IKAMAG magnetic, hotplate stirrer fitted with an IKATRON temperature feedback probe and fuzzy logic controller. Water addition was performed using variable volume Gilson pipettes, Pipetman Classic ${ }^{\mathrm{TM}}$ models: P100, P200, P1000 and P5000. TLC analyses were carried out using Merck $20 \times 20 \mathrm{~cm}, 60 \mathrm{~F}_{254}$ silica gel plates. Glass TLC tanks were fitted with two pieces of Whatman 1 Chr Chromatography paper, $10 \times 10 \mathrm{~cm}$, to act as wicks for the solvent systems. TLC solvent systems were developed using a variety of solvent mixtures selected from chloroform, methanol, ethyl acetate, toluene and hexane solvents modified with up to $1 \% \mathrm{v} / \mathrm{v}$ formic acid to prevent tailing of TLC spots. Solvent system compositions were: $49 \%$ hexane $/ 40 \%$ acetone $/ 1 \% \mathrm{HCOOH}$ with an $R_{f}$ value of $0.39 ; 85 \%$ toluene $/ 14 \%$ EtOAc/ $1 \% \mathrm{HCOOH}$ with an $R_{f}$ value of
0.30 and $90 \% \mathrm{CHCl}_{3} / 9 \% \mathrm{CH}_{3} \mathrm{OH} / 1 \% \mathrm{HCOOH}$ with an $R_{f}$ value of 0.36 . These systems were developed to provide cinnamic acid with a variety of $R_{f}$ values to ensure validation of product authenticity and consistency of reaction profile. Developed TLC plates were visualised using $254 \mathrm{~nm}$ UV light. Melting points were taken on a Kofler hot-stage microscope melting point apparatus and are uncorrected. IR spectra were obtained on a Perkin Elmer Paragon 1000 FTIR spectrometer using standard $\mathrm{KBr}$ disk techniques. NMR spectra were obtained on a $270 \mathrm{MHz}$ JEOL JNM-GX270 FTNMR using deuteriated chloroform and DMSO- $d_{6}$ as solvents with TMS as internal standard.

Vacuum decontamination of $\mathrm{PFA}^{\circledR}$ vessels was carried out for $16 \mathrm{~h}$ under $6 \mathrm{mmHg}$ pressure in a Gallenkamp vacuum oven at $155{ }^{\circ} \mathrm{C}$, fitted with an Edwards, E2M5 vacuum trolley pump operating under full gas ballast.

Sodium carbonate solution decontamination was carried out by immersion of PFA ${ }^{\circledR}$ vessels in a saturated sodium carbonate solution for $72 \mathrm{~h}$ at room temperature.

\subsection{General procedure for atmospheric pressure microwave reactions}

Freshly dried anhydrous sodium acetate $(5.65 \mathrm{~g}, 68.9 \mathrm{mmol})$ was suspended in acetic anhydride (15 mL, $159 \mathrm{mmol}$ ) in a three necked round bottom flask. Benzaldehyde $(7 \mathrm{~mL}, 68.9 \mathrm{mmol})$ was added directly to the mixture and placed in a CEM MAS300 oven and then fitted with three air condensers in line (total dimension: B24 $\times 1200 \mathrm{~mm}$ ) and fitted with an adapter for thermometer and guard tube filled with fresh calcium chloride granules. A $600 \mathrm{~mL}$ glass beaker, which contained $450 \mathrm{~mL}$ of distilled water, was placed in the microwave oven with the reaction assembly in order to absorb reflected microwave energy and thereby avoid damage to the magnetron. The oven was programmed at $60 \%$ power. Every 20 min or so water was added to the beaker in the oven to replace that lost through boiling. The run was complete after $4 \mathrm{~h}$ of microwave irradiation. 
The reaction mixture was allowed to cool to around $80{ }^{\circ} \mathrm{C}$ and the mixture was quenched with water $(20 \mathrm{~mL})$ prior to transfer to a $500 \mathrm{~mL}$ conical flask. The transferred solution was maintained at $80{ }^{\circ} \mathrm{C}$ on a hotplate while a hot, saturated solution of sodium carbonate $(50 \mathrm{~mL})$ was carefully added. Further aliquots of hot, saturated sodium carbonate solution were added, after the initial strong effervescence, until effervescence ceased and a consistent reading of $\mathrm{pH} 10$ was obtained with an indicator test-strip. The hydrolysis and acid dissolution stage could be lengthy if the product was tarry/ oily in any way. A value of pH10 could be achieved quickly and then this value would decrease over time as any tarry or oily product gradually dissolved. Care must be taken to ensure that a consistent $\mathrm{pH} 10$ value is achieved. The reaction mixture was allowed to cool to room temperature and was extracted with diethyl ether $(3 \times 15 \mathrm{~mL})$. The extracts were combined, dried over sodium sulfate, which was removed by filtration, and finally evaporated in vacuo for weighing, TLC analyses and mass balance calculations. The remaining aqueous solution was then acidified with concd $\mathrm{HCl}$ until carbon dioxide evolution ceased. The white precipitate was recrystallized in situ. The recrystallized solution was cooled finally in ice-water for $1 \mathrm{~h}$ prior to isolation by filtration under vacuum. The colourless, crystalline cinnamic acid isolated was dried under vacuum overnight. Melting point $133-134^{\circ} \mathrm{C}\left(\right.$ Lit. Mp, $\left.133^{\circ} \mathrm{C}\right) .{ }^{21}$ IR, NMR and TLC were consistent with authentic material. There was no depression of melting point observed when the isolated cinnamic acid was mixed with commercially available material.

\subsection{General procedure for sealed, microwave Perkin reactions}

Four CEM advanced composite vessels were charged each with freshly dried sodium acetate $(5.65 \mathrm{~g}, 68.9 \mathrm{mmol})$, acetic anhydride $(15 \mathrm{~mL}, 159 \mathrm{mmol})$ and benzaldehyde $(7 \mathrm{~mL}, 68.9 \mathrm{mmol})$. The control vessel was fitted with a temperature probe and topped-up pressure transfer line. The vessels were placed in a CEM MDS2100 microwave oven and the unit was programmed to operate at $80 \%$ power for $4 \mathrm{~h}$ at $147{ }^{\circ} \mathrm{C}$. After $4 \mathrm{~h}$ the reaction mixtures were worked-up as described in the previous experimental method.

\subsection{General procedure for thermally heated, sealed Perkin reactions}

Four CEM advanced composite vessels were charged with reactants at the same scale as in the prior method. The control vessel was monitored for pressure and temperature through the control unit of the CEM MDS2100 oven. All four vessels were placed in a thermostatically controlled, stirred, oil-bath heated at $155{ }^{\circ} \mathrm{C}$ in order to achieve reflux temperature $\left(147^{\circ} \mathrm{C}\right)$ inside the fluoropolymer vessels. After $4 \mathrm{~h}$ at $147^{\circ} \mathrm{C}$ the reactions were worked-up as described in the previous experimental method.

\subsection{General procedure for thermally heated, atmospheric Perkin reactions}

A three neck round bottom flask $(150 \mathrm{~mL})$ was fitted with thermometer $\left(0-250{ }^{\circ} \mathrm{C}\right), 8 \mathrm{~mm}$ PTFE magnetic flea and condenser $(\mathrm{B} 14 \times 230 \mathrm{~mm})$. Reactants were charged in the same order and scale as in the earlier method. The reaction vessel was immersed in a stirred, thermostatically controlled oil-bath at $155{ }^{\circ} \mathrm{C}$. The reaction was heated at reflux for $4 \mathrm{~h}$. After this time the reaction mixture was worked-up as described in the earlier method.

\section{Acknowledgements}

Two of us would like to extend our thanks to D. Lofty of CEM UK Ltd., for the modifications made to the CEM MAS300 microwave oven and the loan of a Holaday, HI 1501 microwave oven leak detection survey meter.

One of us would like to thank W.J.A. Chalkley for the digital preparation of archived instrumental output data.

Professor Alexander McKillop was insistent that his students could demonstrate a firm mechanistic understanding of the reactions that they studied or employed in their organic synthesis research. This article is dedicated to the memory of Sandy's outstanding teaching contribution in this area and his belief that answers lay in the laboratory not in the library. His influence touched many and extended beyond the confines of academia to underpin an industrial career where his insistence on the mechanistic understanding of organic reactions provided a solid foundation for safe, cost-efficient, large-scale pharmaceutical production.

\section{References and notes}

1. Gedye, R. N.; Rank, W.; Westaway, K. C. Can. J. Chem. 1991, 69, 706.

2. Mingos, D. M. P. Baghurst, D. R. J. Chem Soc Rev 1991, 20, 1.

3. Kingston, H. M.; Jassie, L. B. Introduction to Microwave Sample Preparation: Theory and Practice. ACS Professional Reference Book Series; American Chemical Society, 1988

4. CEM Company History, http://www.cem.com/content78.html.

5. Perkin, W. H. J. Chem. Soc. 1868, 21 53, 181.

6. Johnson, J. R. In Organic Reactions; Adams, R., Ed.; John Wiley: New York, NY, 1942; Vol. 1, pp 218-265.

7. Vogel, A. I. A Text-book of Practical Organic Chemistry, 3rd ed.; Longman: London, 1956; pp p.712-713.

8. Abramovitch, R. A.; Abramovitch, D. A.; Iyanar, K.; Tamaraselvy, K. Tetrahedron Lett. 1991, 32, 5251

9. Kaldin, H. In Profiles of Drug Substances, Excipients and Related Methodology; Florey, K., Ed.; Academic: New York, USA, 1982; Vol. 11; Chapter 3 Captopril, p 114.

10. Kalnin, P. Helv. Chim. Acta 1928, 11, 977.

11. Böck, F.; Lock, G.; Schmidt, K. Monatsh. Chem. 1934, 64, 401.

12. Veverkova, E.; Pacherova, E.; Toma, S. Chem. Pap. 1999, 53, 257.

13. Meyer, H.: Beer, R. Monatsh. Chem. 1913, 34, 649.

14. Sykes, P. A Guidebook to Mechanism in Organic Chemistry, 6th ed.; Longman: Scientific \& Technical: Harlow, Essex, UK, 1986; pp 227-228.

15. Kingston, H. M.; Jassie, L. B. Anal. Chem. 1986, 58, 2534.

16. Kinastowski, S.; Kasprzyk, H. Bull. Acad. Pol. Sci. 1978, 26, 907.

17. Mason, C. J.; Edwards, M.; Riby, P. Analyst 2000, 125, 327.

18. Michael, A. J. Prakt. Chem. 1889, 40, 64.

19. Chappell, F. L. Studies of the Perkin Reaction; Cornell University, 1933; (PhD Thesis).

20. Mundy, B. P.; Ellerd, M. G.; Favaloro, F. G., Jr. Name Reactions and Reagents in Organic Synthesis, 2nd ed.; Wiley-Interscience, John Wiley \& Sons: Hoboken, New Jersey, USA, 2005; pp 492-493.

21. Bahadur Singh, N.; Kumar, P. J. Chem. Eng. Data 1986, 31, 406. 